Revista Eletrônica do Mestrado em Educação Ambiental

Revista do PPGEA/FURG-RS

ISSN 1517-1256

Programa de Pós-Graduação em Educação Ambiental

\title{
"Sou ekedi Lara de Oxóssi. Meu nome sou eu e Oxóssi. Não coloca meu nome sozinho não" Notas sobre fotografia e ética nas pesquisas com crianças
}

\author{
Stela Guedes Caputo ${ }^{1}$ \\ Universidade do Estado do Rio de Janeiro \\ https://orcid.org/0000-0003-0133-3301 \\ Cristiano Sant'Anna ${ }^{2}$ \\ Universidade do Estado do Rio de Janeiro \\ https://orcid.org/0000-0002-7797-663X
}

\begin{abstract}
Resumo: Apesar dos métodos visuais nos estudos sociais da infância serem muito comuns, ainda é escassa a discussão sobre esse tipo de metodologia. Bem como é rara a discussão sobre ética nos processos de fotografia e vídeo. Que tensões desafiam os pesquisadores da infância que usam fotografias em suas pesquisas? Quais as normatizações importantes e princípios para os quais devemos ter atenção? O texto que apresentamos é fruto de dois anos de observações, entrevistas, conversas e fotografias com crianças, realizadas em um terreiro de candomblé, em Duque de Caxias, na Baixada Fluminense, além de pesquisa bibliográfica sobre o tema. Concluímos que a discussão sobre os processos fotográficos nas pesquisas com crianças precisa ser ampliada, já que suas tensões podem definir novas e fundamentais abordagens.
\end{abstract}

Palavras-chave: crianças de terreiros; ética na fotografia em pesquisa com crianças; metodologia.

\section{"Soy ekedi Lara de Oxóssi. Mi nombre soy yo y Oxossi. No ponga mi nombre solo" Apuntes sobre fotografía y ética en la investigación con niños.}

Resumen: Aunque los métodos visuales en los estudios sociales de la infancia son muy comunes, todavía hay poca discusión sobre este tipo de metodología. Además, la discusión sobre ética en los procesos de fotografía y video es rara. ¿Qué tensiones desafían a los investigadores de la infancia que usan fotografías en su investigación? ¿Cuáles son las normas y principios importantes a los que

\footnotetext{
${ }^{1}$ Doutora em educação. Professora da UERJ. Coordenadora do Grupo de pesquisa Kékeré (PROPED/UERJ/CNPQ). Este texto, no meu caso, foi escrito enquanto atuava como Professora Visitante Sênior, no contexto CAPES/PRINT, no Instituto de Educação da UMINHO/Braga - Portugal. e-mail: stelauerj@ gmail.com.br

${ }^{2}$ Doutor em educação pelo PROPED/UERJ. Membro pesquisador e vice coordenador do Grupo de Pesquisa Kékeré (PROPED/UERJ/CNPQ). Membro pesquisador do grupo de Pesquisa Narrativas Audiovisuais e Diferença (PROPED/UERJ/CNPQ). Professor SEEDUC/RJ. e-mail: cs-medeiros@ uol.com.br
}

Rev. Eletrônica Mestr. Educ. Ambient. Rio Grande, Dossiê temático "Imagens: resistências e criações cotidianas", p.307-326, jun. 2020. E-ISSN 1517-1256 
debemos prestar atención? El texto que presentamos es el resultado de dos años de observaciones, entrevistas, conversaciones y fotografías con niños, celebradas en un candomblé terreiro, en Duque de Caxias, en Baixada Fluminense, además de la investigación bibliográfica sobre el tema. Llegamos a la conclusión de que la discusión sobre los procesos fotográficos en la investigación con niños debe ampliarse, ya que sus tensiones pueden definir enfoques nuevos y fundamentales. Palabras llave: niños de terreiros; ética de la fotografía en investigación con niños; metodologia

\title{
"I am ekedi Lara de Oxóssi. My name is me and Oxossi. Do not put my name alone"
}

\section{Notes on photography and ethics in research with children}

\begin{abstract}
Although visual methods in social studies of childhood are very common, there is still little discussion about this type of methodology. As well as the discussion about ethics in photography and video processes is rare. What tensions challenge childhood researchers who use photographs in their research? What are the important norms and principles that we should pay attention to? The text we present is the result of two years of observations, interviews, conversations and photographs with children, held in a candomblé terreiro, in Duque de Caxias, in Baixada Fluminense, in addition to bibliographic research on the subject. We conclude that the discussion about photographic processes in research with children needs to be expanded, since their tensions can define new and fundamental approaches.
\end{abstract}

Keywords: children from terreiros; photography ethics in research with children; methodology.

Imagem 1: ekedi Lara de Oxóssi

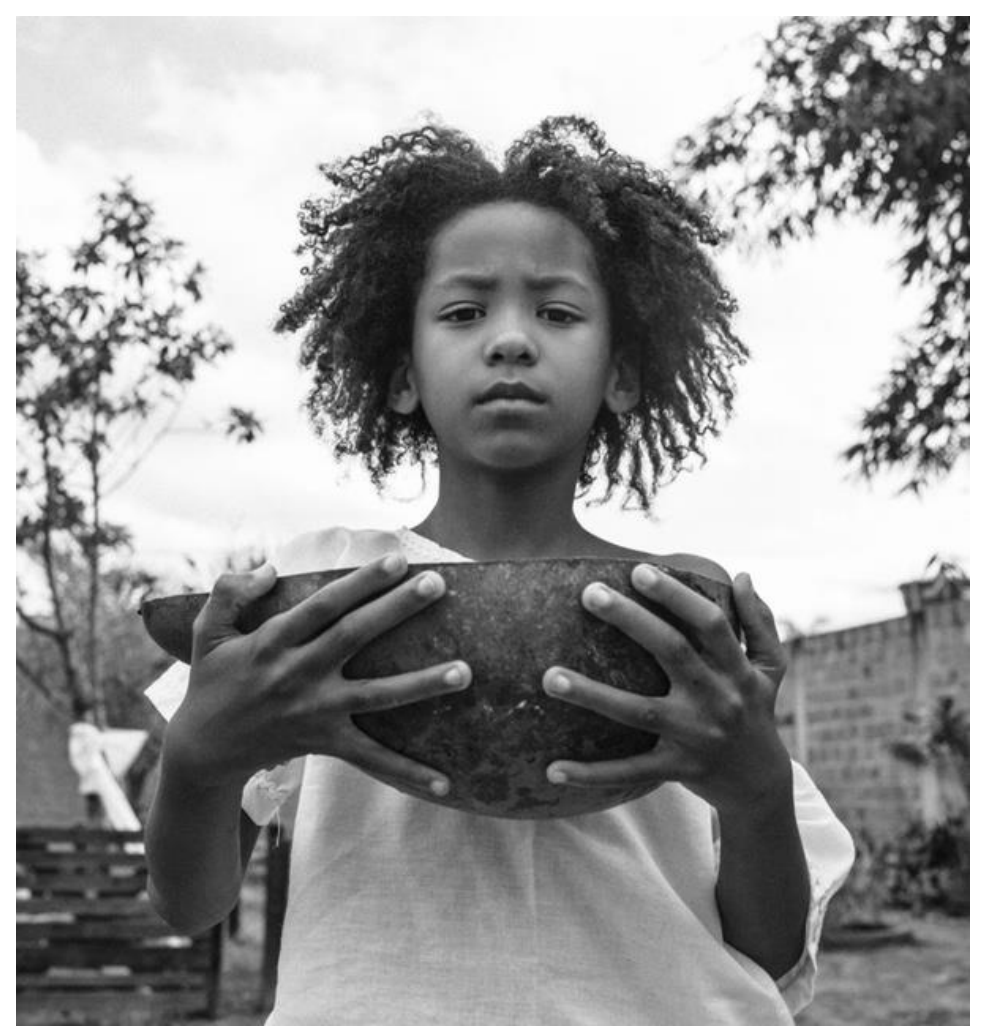

Foto: Stela Guedes Caputo

Rev. Eletrônica Mestr. Educ. Ambient. Rio Grande, Dossiê temático "Imagens: resistências e criações cotidianas", p.307-326, jun. 2020. E-ISSN 1517-1256 


\section{Sobre nomes e caminhos}

A fala que dá título ao nosso artigo é de Lara Tomás Gonçalves, 7 anos, ekedi Lara de Oxóssi. Ela foi dita quando realizávamos um vídeo para nossas pesquisas, no dia 18 de agosto de 2018, no Ilê Axé Omi Lare Iyá Sagbá, um terreiro de candomblé, em Santa Cruz da Serra, Duque de Caxias, Rio de Janeiro. Era dia de Olubajé no terreiro, uma grande festa anual, conhecida como "o banquete do rei”, em homenagem a Obaluayê, orixá da cura, senhor da terra. Conversamos e entrevistamos ekedi Lara de Oxóssi algumas vezes em uma série de visitas realizadas ao seu terreiro no ano de 2018 e 2019. Também a fotografamos e filmamos para a pesquisa, enquanto ela realizava algumas tarefas. Logo no primeiro dia, perguntamos a ela, como gostaria de ser identificada nas fotografias e no vídeo e ela respondeu: "Sou ekedi Lara de Oxóssi. Meu nome sou eu e Oxóssi. Não coloca meu nome sozinho não. Ninguém vai saber que sou eu. Sou ekedi de Oxóssi porque esse é meu orixá". Quatro meses depois, ekedi Lara de Oxossi receberia um cargo no candomblé: òsì de Logun èdé, e diria em outra entrevista: "Porque Logun me suspendeu, me escolheu para ser seu braço esquerdo. Então você já pode colocar o meu nome como ekedi ou òsì de Logun.” A respeito de sua função no candomblé, ekedi Lara de Oxóssi explica que ela não incorpora orixás. "Não incorporo, mas faço muitas coisas importantes e vou fazer mais, aos poucos. Eu posso cuidar de todos os orixás porque sou ekedi, mas depois que Logun me suspendeu òsì, eu agora tenho que cuidar mais de Logun, na minha casa e se eu for em outro terreiro e se precisar cuido também", disse ekedi Lara de Oxóssi. A atribuição de cargos para crianças no candomblé já foi abordada anteriormente (Caputo, 2006, 2012) e Daniel de Yemanjá, Babalorixá do terreiro da ekedi Lara de Oxóssi, entrevistado para nossa pesquisa, reitera: "Um adulto se prepara, uma criança se prepara. Tanto um como outro tem capacidade para os cargos. Uma criança não é menos que um adulto”. A respeito do cargo específico da ekedi Lara de Oxóssi, o sacerdote diz: “A palavra òsì significa esquerdo, o lado esquerdo, o braço esquerdo. Uma função importante para, não só o pai ou a mãe de santo do terreiro, mas da casa. É uma função da casa. Segundo a tradição da nossa casa os cargos de òsì são atribuídos às mulheres e òtún, o lado direito, aos homens. Os dois cargos são fundamentais no terreiro", afirma o Babalorixá.

Partilharemos aqui algumas reflexões a respeito de fotografias em pesquisas com crianças. É fundamento dos Estudos com Crianças de Terreiros (Caputo, 2012, 2018), começar nossos textos com falas de crianças que são sujeitos em nossas pesquisas. Nesse campo de estudos praticamos o que também chamamos de fotoetnografia miúda (Caputo, 
2020), uma etnografia feita com fotografias (tanto estática como em movimento) nos cotidianos dos terreiros, que tem as crianças como principais interlocutores, não só dos diálogos, como também das fotografias produzidas nas pesquisas. Por isso, começamos nosso texto com uma fotografia e com a fala da ekedi Lara de Oxóssi, Osí de Logun èdé. Oxóssi e Logun èdé são orixás. Orixás são deuses ou deusas africanos. Eles foram levados e levadas nos corpos de pessoas africanas escravizadas e chegaram ao Brasil e em muitos outros países, espalhados em diáspora. Oxóssi é um orixá masculino, originário da nação yorubana de Kétu. Já Logun èdé é um orixá adolescente, masculino, originário da cidade yorubana de Ijexá. Ainda hoje, os orixás são vivenciados nos terreiros. Os terreiros são lugares que preservaram e ressignificaram a tradição do culto as orixás e aos antepassados. Existem milhares de terreiros no Brasil. O Ilê Axé Omi Lare Iyá Sagbá, terreiro de ekedi Lara de Oxóssi, é um deles.

Lembramos que o título de nosso artigo é uma resposta, dada pela ekedi Lara de Oxóssi, quando perguntamos a ela como gostaria, como e se preferia ser identificada nas fotografias e no vídeo que produzimos em nossa fotoetnografia miúda. Refletindo a respeito dos usos das metodologias visuais em Ciências Sociais e da Educação, o pesquisador Manuel Jacinto Sarmento (2014), localiza três modalidades que não necessariamente se excluem e podem ser usadas de maneira combinada.

A primeira se refere à produção de imagens. A segunda seria a utilização de imagens pré-existentes e, a terceira, reúne a produção de imagens para a comunicação dos resultados de investigação. Esta última, diz o pesquisador, tem pouco reconhecimento acadêmico e consiste em reduzir o registro exclusivamente escrito dos trabalhos científicos por outros tipos de bases comunicacionais e de linguagens. Inserem-se nessa modalidade, a computação gráfica, as novas tecnologias de comunicação, aliadas na transmissão de resultados científicos. Já a segunda modalidade, explica, é a mais utilizada. Refere-se ao uso da imagem como ilustração ou documentação, tanto em trabalhos acadêmicos, como em pesquisas científicas. Uso, bastante conhecido e divulgado, ainda que, para Sarmento, o tratamento da imagem, a partir dos seus códigos iconográficos, não seja frequente.

A principal e mais importante forma de uso das metodologias visuais, para este pesquisador, é a primeira das modalidades aqui já destacadas. Ou seja, a produção de imagens de investigação. Também é a mais complexa e problemática, já que, em sua opinião, mobiliza maiores cuidados e questões éticas. É a essa modalidade "Produção de Imagens de Investigação", nos estudos da criança, que Sarmento dedica mais tempo de reflexão no capítulo "Metodologias Visuais em Ciências Sociais e da Educação", 
publicado em 2014, no livro "Metodologias de Investigação em Educação e Ciências Sociais".

O texto e as classificações metodológicas apresentadas por Sarmento, não aborda imagens em movimento, mas certamente, com nossa fotoetnografia miúda produzimos imagens na pesquisa, e, por isso, também priorizaremos essa modalidade em nossa reflexão, que terá por objetivo ponderar sobre questões éticas no fazer fotográfico em pesquisas com crianças. Para Fernandes (2016), a discussão sobre ética e pesquisa com crianças não tinha qualquer visibilidade, sendo quase omissa, seja em documentos reguladores dessa relação, seja em publicações acadêmicas. Realidade que, segundo Fernandes, começa a ser alterada justamente quando se registram mudanças no paradigma com base no qual se compreende a criança e a infância, o que para a pesquisadora, lançou as bases para uma renovação ético-metodológica nas relações de pesquisa com crianças.

Argumentaremos em nosso texto que, sim, se por um lado houve mudanças importantes no paradigma com o qual se compreende a criança e a infância, contribuindo, inclusive, para renovações ético-metodológica nessas pesquisas, os processos fotográficos são ainda muito pouco abordados no debate sobre ética nas pesquisas com crianças.

Antes de prosseguir, pedimos que retornem à imagem da ekedi Lara de Oxóssi. O que é preciso para realizar essa fotografia? Mediação com os sujeitos de pesquisa, no caso ekedi Lara de Oxóssi, seus responsáveis legais e, por ser o caso de uma pesquisa em comunidade religiosa, seu responsável religioso? Conhecimento das legislações e códigos de condutas éticas em pesquisas com seres humanos? Conhecimento técnico que permitirá ao pesquisador ou a pesquisadora medir a luz, a velocidade e a sensibilidade, todas questões necessárias a uma foto com qualidade ao menos razoável? Sim, todos esses aspectos são fundamentais e informam o cuidado ético, alimentado por observações contínuas e cotidianas, por escolhas grandes e outras, minúsculas, que estão longe de se resumir a autorizações e assinaturas em papéis (embora autorizações e assinaturas sejam indispensáveis). Sem qualquer pretensão de esgotar o assunto, nosso desejo nesse artigo é conversar um pouco sobre alguns desses cuidados éticos com a fotografia em pesquisa com crianças.

\section{Normas, princípios e ausências}

De acordo com Prado, Vicentin e Rosemberg (2018, p. 45), o debate sobre ética em pesquisa tem se intensificado nas duas últimas décadas, motivado pela ampliação do 
controle social sobre as pesquisas, sendo um de seus marcos, afirmam as pesquisadoras, a promulgação pelo Ministério da Saúde da Resolução 196, em 1996, e de sua substituta, a Resolução 466, de 2012, que regula a pesquisa com seres humanos no Brasil. As autoras destacam que as duas resoluções têm sido criticadas no âmbito das ciências humanas e sociais (CHS) por generalizarem pressupostos das ciências biomédicas para as demais áreas do conhecimento.

Em meio a embates protagonizados pela Comissão Nacional de Ética em Pesquisa e pelo Fórum de Ciências Humanas, Sociais e Sociais Aplicadas, criado em julho de 2013, com associações científicas dessas áreas, uma resolução complementar à 466, específica para essas ciências, entrou em vigor em 2016. A Resolução 510/16 faz avançar o debate sobre o tema, mas mantém acesas controvérsias em torno da regulamentação da ética em pesquisa por esta continuar subordinada ao campo biomédico, dada a sua inserção institucional no Ministério da Saúde. (PRADO; VICENTIM e ROSEMBERG, 2018. p. 45).

Nos limites desse artigo, propomos pensar brevemente sobre três assuntos e de como cada um deles é abordado nas três resoluções. O primeiro assunto se refere aos Consentimento Livre Esclarecido (CLE) e Assentimento Livre e Esclarecido (ALE). Na resolução 196, de 1996, apenas o Consentimento Livre e Esclarecido (CLE) é exigido e mencionado como documento pelo qual os sujeitos de pesquisa e/ou seu representante legal manifestam sua anuência à participação na pesquisa. Na resolução 466, de 2012, o CLE é mantido como documento que expressa, da mesma maneira, a anuência do participante e/ou seu representante legal. Insere-se nessa nova resolução, o Assentimento Livre e Esclarecido (ALE), documento que apresenta a anuência do participante da pesquisa criança ou adolescente, sendo que o ALE não exclui a exigência do CLE. A resolução de 510/2016, que complementou, como descrevemos anteriormente, a resolução 466, mantém tanto o CLE, como o ALE, dando ênfase que o último não exclui o primeiro. Aliás, é justamente a resolução 510/2016, que regula as pesquisas em nossa área, na universidade onde desenvolvemos nossas pesquisas. O segundo aspecto que gostaríamos de pontuar, pela especificidade das pesquisas que desenvolvemos, é que as três resoluções mantém, inclusive com redações quase semelhantes, a exigência de respeitar sempre os valores culturais, sociais, morais, religiosos e éticos, bem como hábitos e costumes quando as pesquisas envolverem comunidades. Por fim, vista nas três resoluções sempre como uma possibilidade de dano, destacamos o terceiro aspecto: a questão da imagem. A exigência dos documentos é que os pesquisadores assegurem a privacidade e a proteção da 
imagem para que os sujeitos de pesquisas não sejam prejudicados ou estigmatizados. E nada além disso.

Temos a impressão de que os procedimentos éticos em relação às fotografias nas pesquisas estejam subsumidos às resoluções que orientam eticamente às pesquisas, sem que os procedimentos fotográficos sejam mencionados profundamente. Isso não seria tanto um problema e explicamos. Para Fernandes (2016), o debate acerca da ética aponta para duas direções. Uma, de acordo com a pesquisadora, considera a importância da existência de regulamentos e códigos éticos ou, mais modestamente, a formulação de princípios éticos. A outra, diz Fernandes, enfatiza a responsabilidade individual e as competências pessoais do investigador por meio de uma perspectiva de contínua reflexibilidade acerca de sua própria prática. "Os princípios e códigos éticos são importantes, mas não são suficientes para abarcar todas as complexidades com que o investigador se confronta no texto de investigação" (Fernandes, 2016, p. 771). Concordamos com o que sugere Fernandes mas, se a perspectiva de contínua reflexibilidade acerca da própria prática dos pesquisadores e pesquisadoras envolvesse a preocupação com a fotografia nas pesquisas com crianças, veríamos muito mais textos e discussões coletivas a esse respeito. O que não acontece, senão muito modestamente, ou até de modo eclipsado. Talvez um exemplo nos ajude no que estamos tentando dizer.

Com objetivo de dar visibilidade ao debate sobre ética em pesquisas com seres humanos realizado por pesquisadores das ciências sociais e humanas, Prado, Vicentim e Rosemberg (2018) analisaram 29 textos publicados em periódicos acadêmicos ou livros até 2016, no Brasil. O corpus de análise para das autoras foi formado por 11 artigos e 18 capítulos de livros que apresentavam discussão sobre ética na pesquisa com criança. Diversos dilemas éticos são abordados e algumas recomendações éticas são apontadas sem que qualquer menção à fotografia ou imagens nas pesquisas com crianças seja feita. Essa ausência já seria uma preocupação porque, de acordo com Sarmento (2014), apesar de uma tendência geral refratária ao uso de metodologias visuais em algumas áreas pouco abertas ao diálogo entre linguagem verbal e linguagem iconográfica, exatamente o oposto, afirma o pesquisador, se verifica no campo dos estudos da criança. Mais notadamente ainda, nos estudos sociais da infância, onde, segundo Sarmento, os métodos visuais, especificamente as etnografias visuais, são bastante comuns.

Se as etnografias visuais são frequentes nos estudos sociais da infância, onde estão as reflexões éticas sobre a fabricação das fotografias nas pesquisas com crianças? Mas esse é apenas uma de nossas preocupações a partir da leitura do levantamento feito pelas 
pesquisadoras. O texto de Sônia Kramer "Autoria e autorização: questões éticas nas pesquisas com crianças", de 2002, é mencionado pelas pesquisadoras que trouxeram em seu artigo exclusivamente sua preocupação com a divulgação dos nomes das crianças pesquisadas e sua preocupação com a divulgação de seus nomes verdadeiros. Bastante conhecido, o texto de Kramer anuncia, logo no resumo, que pretende analisar sim, a utilização dos nomes (verdadeiros ou fíctícios), bem como o uso das imagens, seus rostos, bem como e a autorização do uso dessas imagens tanto em fotografias, vídeos e filmes. Entre tantos dilemas éticos envolvendo fotografias, destacamos abaixo apenas um deles:

No caso das fotografias de crianças, há que se perguntar: quem autoriza a participação, o nome, a gravação? Quem autoriza a utilização de fotografias? Sabemos que é o adulto, e concordamos que é necessário que assim seja, mais uma vez para proteger as crianças, para evitar que suas imagens sejam exploradas, mal usadas. Mas se a autorização quem dá é o adulto, e não a criança, cabe indagar mais uma vez: ela é sujeito da pesquisa? Autoria se relaciona à autorização, à autoridade e à autonomia. Pergunto: como proteger e, ao mesmo tempo, garantir autorização? Como resolver esse impasse? (KRAMER, 2002, p. 53).

Por que esses e outros questionamentos tão importantes a respeito dos processos fotográficos nas pesquisas com crianças, ficaram ausentes de um levantamento que discute ética nas pesquisas? Não sabemos. Mas gostaríamos de seguir com outras ausências.

\section{Utilização de imagens pré-existentes}

Embora estejamos priorizando em nossa reflexão, a modalidade "produção de imagem de investigação", no texto já citado de Sarmento (2014), o pesquisador destaca a importância da "utilização de imagens pré-existentes", classificada por ele, como vimos, de segunda modalidade de metodologias visuais. Essa modalidade refere-se ao uso da imagem como ilustração ou documentação, tanto em trabalhos acadêmicos, como em pesquisas científicas. Apesar de considerar que o tratamento dos códigos iconográficos não seja frequente nessa categoria, o autor destaca sua frequência tanto no uso como na divulgação. Embora Sarmento também afirme que a metodologia de produção de imagem de investigação seja mais complexa e problemática, porque mobiliza maiores cuidados e questões éticas, não podemos deixar de dizer que, em nossa opinião, a categoria da utilização de imagens pré-existentes é igualmente complexa, problemática e exige cuidados e preocupações éticas. É sobre isso que desejamos discutir nesse ponto de nosso texto. Para tanto, usaremos um conjunto de imagens que reúne três fotografias, alteradas 
primeiramente no aplicativo "PicsArt", onde ganharam traços de aquarela. A intenção da mudança foi distanciar um pouco o reconhecimento das pessoas fotografadas (já que não somos autores das fotos, não sabemos como e se as imagens foram autorizadas). A segunda mudança foi a montagem que reuniu no aplicativo "Collageable", as três fotografias antes separadas. O objetivo da montagem foi preservar espaço no texto e facilitar a reflexão com disposições mais aproximadas. Essas fotografias foram feitas no dia 25 de outubro de 2019, durante o seminário "Guimarães, cidade amiga da criança - os 30 anos da Convenção dos Direitos da Criança”, realizado no Centro Cultural Vila Flor, em Guimarães.

Imagem 2: Montagem no Collageable feita a partir de fotos fotografias feitas no dia 25 de outubro de 2019, durante o seminário "Guimarães, cidade amiga da criança - os 30 anos da Convenção dos Direitos da Criança".

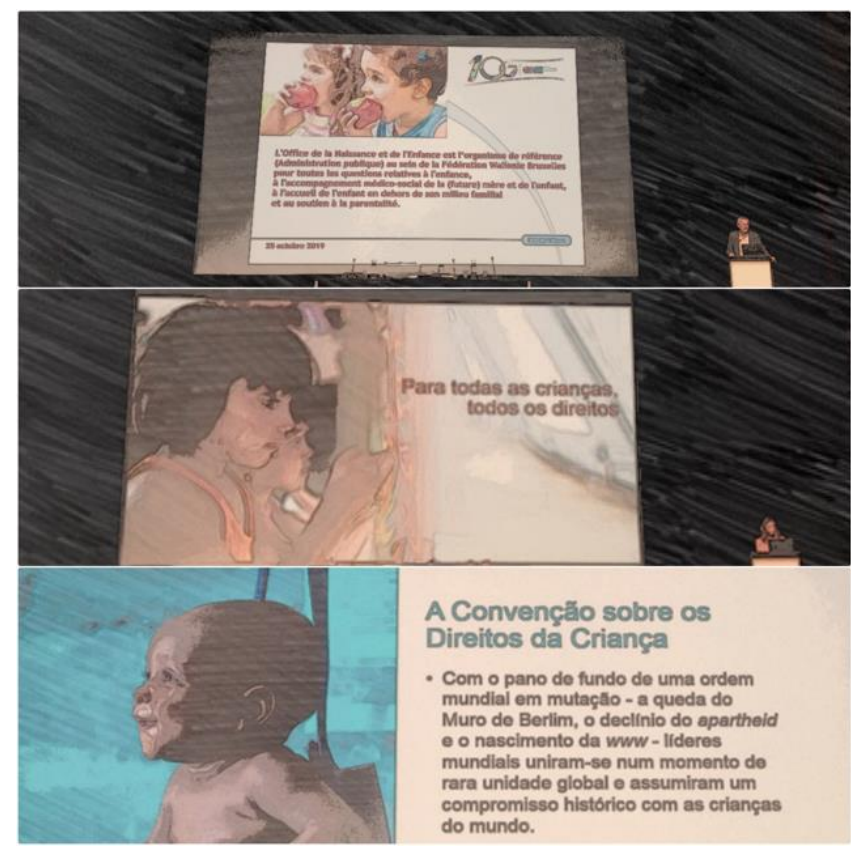

Montagem da fotos: Stela Guedes Caputo

Todas as três fotografias de crianças do primeiro grupo, acima, estavam em powerpoints de apresentações de dois palestrantes, convidados para o seminário. Nenhuma das imagens dialoga com as informações apresentadas. Não sabemos quem são as crianças, seus nomes, suas idades, em que país vivem. Na primeira fotografia não sabemos porque duas crianças estão comendo uma maçã, não há qualquer relação da imagem com qualquer reflexão apresentada. Na segunda, a fotografia de uma criança indígena talvez tenha sido a escolha para ilustrar a frase "para todas as crianças, todos os direitos". Pelo mesmo motivo, 
uma fotografia de um bebê (ou uma bebê) negro, ou negra, serviu perfeitamente para ilustrar o slide que se referia ao apharteid.

Não havia crédito nas fotografias. Ou seja, não havia nomes do fotógrafo ou fotógrafa realizadores da fotografia. As fotografias dos slides também não foram produzidas pelos pesquisadores. Ao menos é o que podemos supor, já que não dialogam com os dados apresentados pelos dois palestrantes, bem como não acrescentam informações. Imaginamos possíveis origens dessas imagens, listadas a seguir por ordem de maior probabilidade: 1 - Banco de imagens das entidades representadas pelos palestrantes; 2 - Banco de imagens pagos ou gratuitos; 3 - Imagens aleatórias disponíveis na internet. Para o que vamos conversar brevemente aqui e para o que pretendemos argumentar e defender, qualquer dessas origens imaginadas não fará diferença. Já que não foram realizadas pelos palestrantes, o mais importante, para a breve reflexão neste item, é o uso de imagens pré-existentes nas pesquisas e suas apresentações.

Pensando em como essas imagens são apresentadas sem nomes, sem época, sem lugar, talvez o conceito de "imagem-fantasma" do pesquisador Michael Abrantes Kerr (2012), seja oportuno. Muito utilizadas atualmente, principalmente, no que denominamos sociedade do compartilhamento (Sant'Anna, 2017), Kerr refere-se a imagens de arquivo sendo aquelas aproveitadas, copiadas e compartilhadas para fins distintos dos que as geraram. Essas imagens estão disponíveis em bancos de dados digitais de sites como o de busca Google e as redes sociais da internet, como o próprio Facebook e o YouTube, que possibilitam que os usuários copiem, colem, publiquem, editem e compartilhem variadas imagens, seja a fotografia, imagens de arte ou audiovisuais, de diferentes autores.

Para Kerr, existem seis pistas, denominadas pelo autor de "seis atos" para abordagem do que denominou "imagem-fantasma". Especificamente para nossa discussão, abordaremos apenas alguns desses atos. No primeiro ato, “o fantasma e a forma [...], já havia uma manipulação para a composição de uma imagem que parecia ser natural” (Ibid., p. 49). O autor discute a manipulação da imagem. Essa não é só uma questão da atualidade, como fazemos com o uso dos smartphones que possuem diversos filtros e programas que podemos aplicar e modificar a imagem. No segundo ato, "fantasmas, redes sociais e banco de dados" (Ibid., p.50), estão muitas imagens, a partir de banco de dados disponíveis na internet, utilizadas para produzir audiovisuais. A lógica, para o autor, está na busca e na montagem de diferentes contextos em uma nova utilização, dizendo novas mensagens. No que chamou de sexto ato, "abrir-se ao desconhecido na construção de uma 
nova ecologia da imagem" Kerr nos fala da utilização das "imagens-fantasmas" nos processos de elaboração de novas imagens, principalmente do audiovisual.

É neste sentido que tento abrir a noção de imagem-fantasma como toda imagem de arquivo que é utilizada em um novo contexto, diferente da sua origem. É assim que proponho o jogo da reutilização de imagens como duplos, que são mortas e vivas ao mesmo tempo. (KERR, 2012, p. 55).

Exclusivamente para nossas preocupações, nos interessa perguntar, em que medida uma imagem de arquivo, portanto, uma imagem-fantasma utilizada ad-eternum mobiliza questões éticas nas pesquisas com crianças? As crianças mostradas nas imagens acima podem estar muito velhas agora e suas fotografias continuarão fixas para sempre sem que saibamos seus nomes, sem termos ouvido suas falas, sem conhecermos ao menos vestígios de suas histórias.

Se uma pesquisa traz texto e fotografias somos instigados (ou ao menos deveríamos ser) a pensar e questionar tanto o texto como as imagens. Isso vale (ou deveria valer) do mesmo modo, tanto para nós que produzimos imagens para nossas pesquisas, como para quem usa fotografias pré-existentes para suas pesquisas e apresentações das mesmas. De onde vem essa informação do texto? De onde vem essa informação da fotografia? Como se produziu esse texto? Como se produziram essas fotografias? São perguntas que envolvem ética na produção e uso, como envolve também a confiança nos relatos textuais e imagéticos. O historiador Peter Burke, por exemplo, já perguntou "Como confiar nas fotografias"? em artigo publicado no Caderno Mais, da Folha de São Paulo, no dia 4 de fevereiro de 2001. Burke destaca, mais uma vez, aliás, a velha oposição entre o entusiasmo e o desprezo que marca a história da fotografia. Como exemplo de um historiador entusiasta, cita Robert Rosenstone que defende a "escrita" da história por meio da realização de filmes, chegando a conceituar o processo de "historiotofia". Já outros rejeitavam essa tendência alegando que a câmera fotográfica não é confiável.

A opinião de Burke no debate, muito mais desenvolvido, inclusive, em seu livro "Testemunha Ocular - História e Imagem", escrito nesse mesmo ano, é de que o uso crescente de fotografias e outras imagens como fontes históricas pode enriquecer muito nosso conhecimento e nossa compreensão do passado, desde que critiquemos a fonte, do mesmo modo que fazemos com depoimentos e outros textos escritos.

Sim, acreditamos também nós, que a fotografia, apesar de toda manipulação a que pode estar submetida, não merece menos confiança que os textos, mas ambos, texto e fotos, aos menos para nossas pesquisas, precisam informar suas fontes. Até porque vemos 
a fotografia não apenas como fonte de compreensão do passado, mas como fonte, método e teoria de interrogação do passado e do presente. E, talvez até, como modo de sonhar o futuro.

\section{A importância do nome}

A primeira vez que eu nasci foi em 1935. Não tenho nenhuma lembrança o que vivi nas duas vezes. Nada! Essa é uma de nossas limitações, cara: não saber de onde a gente veio. De qualquer forma, quando eu nasci, meu pai quis imitar seu próprio pai. Ambos eram pastores protestantes. Bem, para agradar a um desses brancos aí, meu pai pediu a um missionário alemão pra me dar um nome; dá pra imaginar isso, cara? Um branco dando nome a uma criança africana? Na África, cara, onde os nomes são levados tão a sério! Tem até uma cerimônia do nome especial cada vez que uma criança nasce. Sem isso, dizem que uma criança não consegue entrar de verdade no mundo dos vivos. E só para agradar algum missionário branco...meu próprio pai... Ah, não, cara! Nããão! (...) Carregar o nome dos conquistadores? Ou rejeitar essa primeira chegada ao mundo? Os orixás, eles me ouviram. E eles me pouparam. Duas semanas após meu primeiro nascimento, minha alma deixou meu corpo pra voltar ao mundo dos espíritos. (MOORE, 2011, p. 26).

O depoimento acima é de Olufela Olusegun Oludotun Ransome-Kuti, mais conhecido como Fela Anikulapo Ransome Kuti, ou simplesmente Fela Kuti. Um multiinstrumentista nigeriano, músico e compositor, pioneiro do gênero musical afrobeat, ativista político e dos direitos humanos, em sua biografia, escrita pelo pesquisador Carlos Moore. A citação nos mostra como, para as culturas dos povos africanos, o nome é uma questão de vida ou de morte. A cerimônia do nome mencionada por Fela também acontece nos terreiros de candomblés. Alguns chegam a manter o ikómojàde, uma cerimônia de batizado dar nome ao recém nascido, que envolve enterrar a placenta e cordão umbilical aos pés de uma árvore frondosa.

Assim, a criança receberá seu nome conforme seu clã, ou origem espiritual, ou ainda conforme as características de sua energia. Após, há um rito no qual a criança batizada é sacralizada com elementos mágicos, como o dendê, o sal, cana de açúcar, mel, a terra, peixe, etc. Denominado também como culto à placenta. Conforme a mitologia yorubá, a placenta (olóbi) é impregnada pelas últimas lembranças do espírito que escolhera seu destino, antes de nascer. Enterrar a placenta na terra é solidificar as escolhas feitas antes de nascer, para que se cumpram durante sua permanência no mundo. (JAGUN, 2017, p. 343). 
Um outro momento que nos traz a importância do nome para os candomblecistas, se refere à "cerimônia do nome" (dárúko) quando o orixá do iniciado diz publicamente o seu nome. Não é à toa que ekedi Lara de Oxóssi faz questão de, ao optar por identificar suas fotos com seu próprio nome, exigir também que não coloquemos seu "nome sozinho". A companhia de seu orixá foi definida por ela, como elemento fundamental para sua identificação em nossos textos e vídeos.

Por outro lado, quando crianças de candomblé optam por serem identificadas com outros nomes que não sejam os seus próprios, não significa que não reconheçam a importância de seus nomes para suas histórias de vida e de suas comunidades. Significa que sim, elas sabem dessa importância, mas identificam também a perversidade do racismo em nossa sociedade e escolhem outros nomes como estratégias de menos sofrer (Caputo, 2012).

De todo modo, é a criança que, também em diálogo com seus responsáveis, decide que fotos suas serão usadas e com qual nome prefere ser identificada. Não sabemos como operam as agências de publicidade ou os bancos de imagens que disponibilizam fotografias de crianças para inúmeros fins. Para nós que não somos publicitários e sim pesquisadores, os princípios são outros. Voltemos, por gentileza, às fotos trazidas no subitem "Imagens pré-existentes" e pensemos: qualquer uma daquelas imagens poderia ser substituída por uma outra fotografia de criança. Não faria a menor diferença na apresentação, se: 1 - elas fossem trocadas entre si; 2 - fossem substituídas por outras fotografias de outras crianças, 3 - fossem substituídas por imagens de barquinhos de papel, pipas (papagaios) ou lápis de cores, tão comuns em apresentações cujo tema sejam as crianças. Para nós que praticamos em nossas pesquisas, nossa fotoetnografia miúda, uma fotografia de criança é insubstituível porque sua história é insubstituível. Nós só podemos trocar seu nome se a criança decidir que troquemos, mas ela saberá que trocamos e que contaremos a história que ela nos permitiu contar.

Afirmamos que os Estudos com Crianças de Terreiros, seguem pareados com a Sociologia da Infância, para quem a infância é uma categoria do tipo geracional e percebe as crianças como atores sociais de pleno direito, a partir do seu próprio campo, priorizando suas falas (Sarmento, 2008, p. 22). Gostaríamos de afirmar que a observação desse direito não pode subtrair o direito da criança sobre seu corpo (ènìa em yorubá) nas fotografias de pesquisas. Muito significativamente, aliás, a palavra imagem (àwòrán, retrato, aparição, em yorubá), seja, possivelmente, derivada de àwò (mistério) e ìrán (transe, visão, 
aparição) $)^{3}$. Nos permitimos supor que a imagem de cada pessoa traga e guarde seu próprio segredo, seu mistério instransponível e insubstituível.

É por isso também que discordamos de muitas legendas em fotografias de pesquisas em que as pessoas desaparecem nos grupos étnicos, por exemplo. Em geral, em etnografias com indígenas, a legenda invariavelmente é "criança indígena". Sabemos que existem muitas singularidades entre os povos. Em algumas etnias, a criança só recebe o nome a partir de uma certa idade, então, se o nome não pode estar na foto, a explicação dessa ausência nos parece fundamental. Cada nome carrega uma história e, a ausência do nome sempre terá, do mesmo modo, uma história para contar.

\section{A cabaça era pra quê?}

Imagem 3: ekedi Lara de Oxóssi e Eloá de Yansã

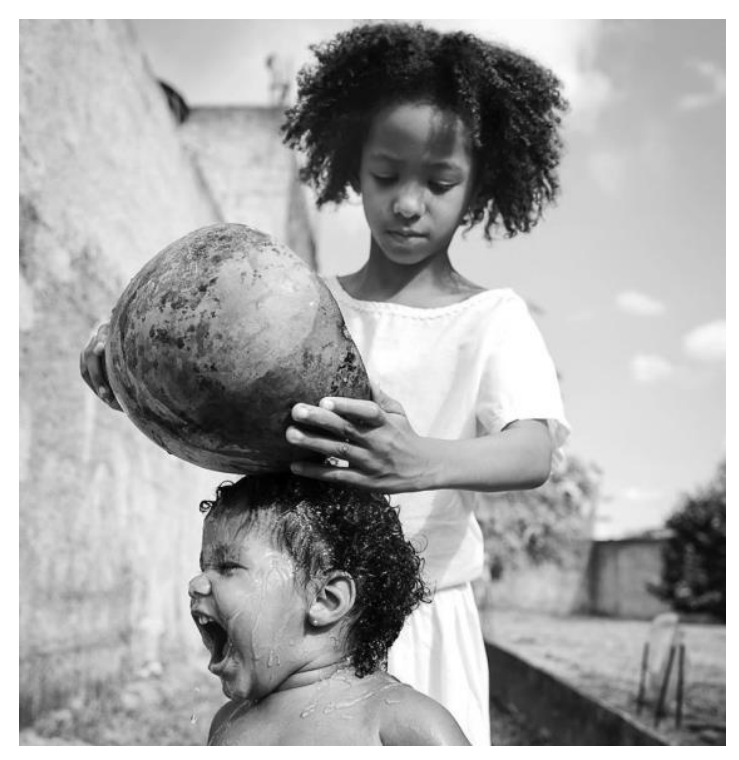

Fotografia: Stela Guedes Caputo

Para Santaella (2012), ler uma foto é lançar um olhar atento àquilo que a constitui como linguagem visual, com as especificidades que lhe são próprias.

Assim, uma vez diante da fotografia, trata-se de buscar a unidade melódica de suas luzes, linhas e direções, suas escalas e volumes, seus eixos e suas sombras, enfim, contemplar a atmosfera que ela oferta ao olhar, pois a significação imanente dos motivos e temas fotográficos é inseparável do arranjo singular que o fotógrafo escolheu apresentar. (SANTAELLA, 2012, p. 80).

\footnotetext{
${ }^{3}$ Traduções em conversas por celular, no dia 12 de janeiro de 2019, realizadas por Márcio de Jagun.
} 
Santaella tem razão, cada foto é uma escolha construída, ao menos pensamos assim, por uma longa relação no campo com os sujeitos da pesquisa. Uma foto nunca é feita no momento em que nosso dedo indicador aperta aciona o botão de disparo de nossas câmeras. Ela guarda uma sucessão de dias e noites de observações antigas. Ela é feita de anterioridades e de olhos velhos, envelhecidos no campo.

Além das percepções das luzes, sombras, linhas e direções das quais nos falou Santaela, cada fotografia oferece muito mais. Ela trará gestos, atitudes, artefatos cotidianos. O que fazia a ekedi Lara de Oxóssi carregando uma cabaça nas mãos na abertura de nosso texto. Aliás, o que é uma cabaça? Cabaça, igbá, cuia; fruto do cabaceiro - Cucurbita lagenaria (Lagenaria vulgaris). A folha da cabaceira, diz Jagun, (2017), é considerada uma erva forte para desfazer feitiços maléficos. Utensílio cotidianamente utilizado nos candomblés tanto como paramento de diversas divindades, como cuia para banhos, vasilhame para culinária, em inúmeros rituais e também para percussão. Na primeira foto, ekedi Lara de Oxóssi carregava água para dar banho em outra criança, dofonitinha ${ }^{4}$ Eloá de Yansã, de 2 anos, sua irmã de santo. Uma fotografia faz isso: nos ajuda a perguntar.

A cabaça inteira, também de acordo com Jagun, simboliza a ligação entre o céu (òrun) e a Terra (àiyé), enquanto estes ainda eram unidos. Já a cabaça partida ao meio no sentido horizontal representa o equilíbrio entre o masculino e o feminino. A cabaça pode ter diferentes formatos, cada qual, cortada conforme o interesse, ganha uma denominação e destinação próprias, mediante sua utilização. 'Uma ekedi ajuda em muitas coisas todos os dias. Hoje tem festa e eu amo Olubajé. Não posso ficar sentada esperando a festa chegar. Já fiz cordão de pipoca, já enfeitei o barracão, ajudo a dar banho. Não é porque sou ekedi que não vou ajudar. Todo mundo tem que estar prontinho na hora que começar”, nos disse a ekedi Lara de Oxóssi.

Uma discussão que não poderíamos deixar de fazer, ainda que superficialmente é a seguinte: por ser uma religião de àwò (segredo, mistério), em muitos casos, a fotografia no candomblé é vista como uma profanação desse segredo. Nessas casas, o pai ou a mãe de santo, não darão permissão para fotografar, ou, ao menos, as restrições serão muitas. Por outro lado, como disse Caputo (2018), há quem aposte na fotografia como afirmação identitária, daí a proliferação de todo tipo de foto, incluindo selfies, de candomblecistas e umbandistas com roupas tradicionais nos cotidianos dos terreiros e, até mesmo, fotos dos

\footnotetext{
${ }^{4}$ Dofonitnha significa a segunda posição em um barco de iniciação, ou seja, no grupo de pessoas que se iniciaram juntas. Yansã é o Orixá da menina. Orixá feminino africano associado aos ventos.
} 
Orixás incorporados e cerimônias mais fechadas. O candomblé não é uma religião centralizada. Cada casa define a respeito do funcionamento da própria casa e de seus ritos, em geral, ligados a uma casa matriz.

Essas circunstâncias singularizam os cuidados éticos nas pesquisas que fazemos com crianças de candomblé. Outras singularidades desenharão os cuidados éticos de outros pesquisadores. Uma questão de ordem deontológica que, como diz Mathias (2016), indaga sobre o que pode ser mostrado, que situações podem ser gravadas, pois nem todas as práticas culturais podem ser vistas por todos e ainda assim, quando podem, afirma, nem sempre se mostram como de fato se constituem. "Existe então uma ética tanto na produção quanto na reprodução das imagens que muitas vezes não se correspondem”. (Mathias, 2016, p.42-43).

\section{Ética e estética antirracista nas pesquisas com crianças}

\section{Considerações Finais}

Imagem 4: ekedi Lara de Oxóssi

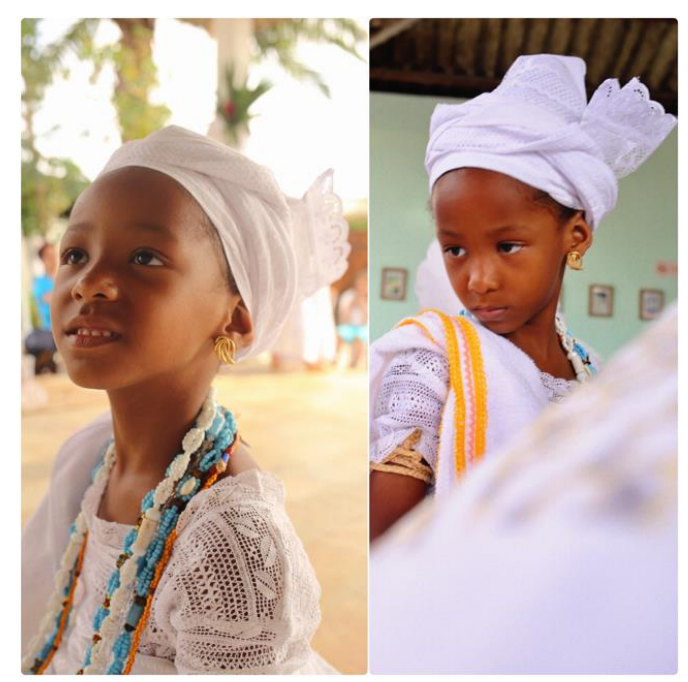

Fotografia: Stela Guedes Caputo

As fotografias acima foram feitas no mesmo dia das fotografias anteriores de ekedi Lara de Oxóssi compartilhadas já nesse texto. Nas fotos, ela usa brinco grande, ojá (seu pano de cabeça) com uma orelha (aba) apenas. A função do ojá é proteger o ori (cabeça) do iniciado, ou iniciada. Por ter um orixá masculino (Oxóssi), ela usa uma aba apenas. Se o orixá fosse feminino, usaria duas abas. Como ekedi Lara de Oxóssi é do gênero feminino, 
a aba de seu ojá será sempre no lado esquerdo. Ela também carrega sua toalha de ekedi no ombro. Suas contas (colares), são de pessoa de grau, ou seja, mostra que é uma pessoa com cargo. Nenhum desses artefatos são meros enfeites, todos possuem fundamentos, bem como evidenciam hierarquia, tempo de santo e outros muitos detalhes que, para pesquisadores, vão se tornando perceptíveis com o tempo.

Nesse momento final de nosso texto, gostaríamos de destacar que inscrevemos nossos estudos no que o sociólogo George J. Sefa Dei chama de "Metodologias de Investigação Anti-Racistas". Para ele, todo pesquisador deve reconhecer o impacto crucial da raça e da diferença social e, junto com isso, reconhecer as relações de poder assimétricas estruturadas no contexto da diferença. De acordo com o sociólogo, a busca da investigação antirracista suscita uma enormidade de questões teóricas e metodológicas complexas.

$\mathrm{O}$ anti-racismo ${ }^{5}$ tem que ver com relações de poder. O discurso antiracismo afasta-se de discussões sobre a tolerância da diversidade e aproxima-se da noção de diferença e poder. Vê a raça ${ }^{6}$ e o racismo como centrais em relação ao modo como reivindicamos, ocupamos e defendemos os espaços. A tarefa do anti-racismo é a de identificar, desafiar e mudar os valores, as estruturas e os comportamentos que perpetuam o racismo sistemático e outras formas de opressão social. (DEI, 2008, p. 17).

Para Sefa Dei, a investigação (ou pesquisa) antirracista é operacionalizada como uma investigação sobre a dominação racial e a opressão social e requer uma nova mudança de paradigma, "um paradigma distante da investigação colonial e próximo de uma abordagem relacional genuína com os sujeitos locais para desvendar as relações de poder na produção, interrogação, validação e disseminação do conhecimento". (idem, p. 25).

Nos limites desse artigo, indicaremos algumas características das metodologias de pesquisa antirracista sugeridas por Sefa Dei:

* Reconhecimento do pesquisador de um entendimento de que as características pessoais influenciam o sucesso da investigação e das parcerias significativas com os sujeitos de estudo;

* Afirmam a base de conhecimento dos sujeitos de estudos;

* Ligam a questão da identidade à produção do conhecimento;

\footnotetext{
${ }^{5}$ Mantivemos a grafia do original.

${ }^{6}$ Raça aqui entendida, evidentemente, não como conceito biológico, mas como categoria de análise sociológica.
} 
* Ajudam a desafiar as relações coloniais e imperiais, subvertendo modos hegemônicos de saber;

* Colocam questões sobre quem está a falar, sobre o quê e para quem;

* Levantam questões acerca dos contextos sociais e políticos da produção de conhecimento, bem como sobre as fontes e usos dos dados de investigação;

* Assumem que há racismo institucional na investigação em ciências sociais mainstream. Isto é evidente nos tópicos de estudo, nos conceitos e metodologias privilegiados, a quem é permitido, legitimado e validado pesquisar, o quê e como as estruturas existentes permitem a produção e disseminação de certos saberes;

* A questão da relevância é um elemento chave na investigação antirracista. A relevância é definida aos olhos dos sujeitos de pesquisa, não aos olhos do investigador e dos financiadores do projeto de pesquisa.

* Reconhecem um código ético para investigar a opressão social e de raça. Um código que reconhece o impacto do racismo sobre os quadros teóricos e conceituais, as epistemologias e as metodologias de investigação nos chamados "estudos científicos";

* Assim, a ética e os conceitos chave que subjazem aos objetivos da investigação, e ao ethos, desenho, orientação, aplicação e disseminação do conhecimento de investigação devem ser guiados por princípios antirracistas de múltiplos modos de saber e pela necessidade de procurar uma representação plena e a inclusão de experiências variadas;

* Empenha-se explicitamente em promover objetivos antirracistas, e particularmente em desafiar a dominação e as relações de poder na sociedade através da promoção da justiça social, da equidade e da justeza,

* Reconhece a ideia de ligar as opressões, privilégios diferenciais, simultaneidade de opressões e privilégios, e as imbricações da raça, do gênero, da sexualidade e das identidades de classe (inserimos: das culturas, incluindo as religiosas) - como prova das complexidades das experiências vividas.

Perguntamos, mais uma vez, com Sefa Dei: Quem está a falar nas pesquisas com crianças? E para quem falam? Que histórias buscamos? Por quais histórias nos interessamos como pesquisadores e pesquisadoras? Temos perguntado a muitos pesquisadores que fazem etnografias: "Quando você começa e pensar em ética?" Com raríssimas exceções a resposta é sempre: "quando começo as observações de campo".

Contudo, gostaríamos de dizer que, para nós, a ética começa com a escolha do assunto e dos sujeitos. Sobre que temas estamos falando? Com quem estamos pesquisando? Isso obrigatoriamente irá definir o modo como fazemos fotografia em nossas 
pesquisas. Embora Sefa Dei não tenha incluído a questão da imagem ao falar de metodologia, achamos fundamental incluí-la e perguntar: quem fotografamos e que narrativas visuais estamos construindo? Por fim, propomos pensarmos mais coletivamente algo que estranhamente parece apartado de nossas reflexões etnográficas: que tipo de estética temos construído e que tipo de estética temos tentado destruir? Uma estética do branqueamento? Que, segundo Araújo (2006) torna-se o padrão de referência e reproduzem estereótipos sobre negros e negras e alimentam o projeto comum de branquitude em todas as mídias? Ou construímos imagens desestabilizadoras (Santos, 1996), criadas a partir das culturas silenciadas e marginalizadas e que, uma vez produzidas com os sujeitos do campo, desestabilizem a lógica colonial e produzam outros espaços de conhecimento e poder?

Em nossas pesquisas, reafirmamos a opção de produzir imagens desestabilizadoras com as crianças de terreiros. Acreditamos que só existe ética em pesquisa se nossas pesquisas forem antirracistas. Quando nossas pesquisas envolverem fotografias, do mesmo modo, só estaremos sendo éticos se a estética construída for igualmente, uma estética antirracista. Achamos que são por essas tensões com as quais finalizamos nosso trabalho, que todo debate sobre ética e fotografia nas pesquisas com crianças deve começar.

\section{Referências}

ARAÚJO, Joel Zito. A força de um desejo - a persistência da branquitude como padrão estético audiovisual. In: Revista USP. N.79. São Paulo. 2006.

BURKE, Peter. Como confiar em fotografias. Folha de S. Paulo, Caderno Mais, 04 fev. 2001.

CAPUTO, Stela Guedes. Fotografia e outros desafios digitais nas pesquisas com crianças. Aracaju. Revista Interfaces Científicas. v. 8. N3. 2020.

CAPUTO, Stela Guedes. Reparar Miúdo, Narrar Kékeré - Notas sobre nossa fotoetnopoética com Crianças de Terreiros. Revista Teias, v. 19, n. 53, abr./jun. 2018

CAPUTO, Stela Guedes. Educação nos terreiros e como a escola se relaciona com crianças de candomblé. Rio de Janeiro: Pallas, 2012.

CAPUTO, Stela Guedes. Educação em terreiros de candomblé - contribuição para uma educação multicultural crítica. In: CANDAU, Vera Maria. Educação Intercultural e cotidiano escolar. Rio de Janeiro: 7 Letras, 2006.

DEI, George J. Sefa; JOHAL, Gurpreet Singh (org). Metodologias de Investigação AntiRacistas - Questões Críticas. Portugal: Edições Pedagogo, 2008. 
JAGUN, Márcio. Vocabulário Temático do Candomblé. Rio de Janeiro: Litteris, 2017.

KERR, Michael Abrantes. Em busca de uma ecologia da imagem-fantasma. In:

MONTANO, Sonia; FISCHER, Gustavo, KILPP, Suzana (orgs). Impactos das novas

mídias no estatuto da imagem. Porto Alegre: Meridional, 2012.

KRAMER, Sônia. Autoria e autorização: questões éticas nas pesquisas com crianças.

Cadernos de Pesquisa. n. 116. Julho, 2012.

MOORE, Carlos. Fela, essa vida puta. Belo Horizonte: Nandyala, 2011.

FERNANDES, Natália. Ética com crianças: ausência e desafios. In: Revista Brasileira de Educação. ANPED, Rio de Janeiro: 2016.

PRADO, R.L.C; VICENTIN, M.C; ROSEMBERG.F. Ética na pesquisa com crianças: uma revisão da literatura brasileira das ciências humanas e sociais. Childhood \& Philosophy, Rio de Janeiro, v. 14, n. 29, 2018.

SANTAELLA, Lucia. Leitura de Imagens. São Paulo: Melhoramentos, 2012.

SANT'ANNA, Cristiano. \#DIFERENÇA: pensando com imagens dentrofora da escola. Tese de doutorado, Proped/UERJ, 2017. Disponível em www.proped.pro.br

SANTOS, Boaventura Sousa. Para Uma Pedagogia do Conflito. In: SILVA, L.H;

AZEVEDO, J.; SANTOS, E. (orgs.). Reestruturação Curricular: novos mapas culturais. novas perspectivas educacionais. Porto Alegre: Sulina, 1996.

SARMENTO, Manuel Jacinto. Metodologias visuais em ciências sociais e da educação. In: Torres, L. e Palhares, J-A. (org.). Metodologias de Investigação em Educação e Ciências Sociais. Braga: Húmus, 2014.

SARMENTO, Manuel; GOUVEA, Maria Cristina Soares. Estudos da Infância, Educação e Práticas Sociais. Petrópolis: Vozes, 2008.

Submetido em: 04-05-2020.

Publicado em: 01-07-2020. 